grown in the vicinity of Ft. Vermillion at an average yield of 24 bushels per acre. Two stone mills and a modern roller mill are established at this point, which is 350 miles north of Edmonton. The wheat grown is probably not the best but appears to be of fair quality and has a fine appearance.

A similar line of reasoning to that in the above statements, which will not be given here in the desire for brevity, will lead one to the conclusion that European Russia may increase her production at least 600 ,000,000 bushels or to a total of $1,300,000$,000 bushels. Argentina's wheat production has increased with unusual rapidity since 1904, reaching now an average of over 150,000,000 bushels. Three times that amount, or $450,000,000$ bushels, is a low mark to set for that country's attainment by 1950 . The most perfectly adapted area of the country for wheat lies in the southern part-old Patagonia-and is yet largely unexploited agriculturally. The wheats of best quality so far produced in Argentina come from the Chubut district in the northern part of this area.

The possible increases in foreign production just mentioned amount to about $1,500,000,000$ bushels, which, added to the $900,000,000$ bushels increase estimated for this country, gives a total of $2,400,000,000$ bushels increase in production for the chief exporting countries. On the basis of previous relations of population to wheat production, and considering the increase in substitute foods that is sure to occur, the world will require, we may suppose, about $5,500,000,000$ bushels of wheat by 1950 , an increase of $2,000,000,000$ bushels over present production. The above estimated total increase more than satisfies this requirement.
U. S. Department of Agriculture

\section{MISS MATILDA H. SMITH}

' THe older members of the American Association will learn with regret of the death of Miss Matilda H. Smith, of Pittsburgh, Pa.

Miss Smith, with her sister, Miss Jennie M. Smith, has frequently been in attendance at the meetings in past years and has always taken a great interest in the advancement of science in a broad way.

Some years ago, they thought out a very original plan by which to aid the association in its general aims and at the same time to encourage certain scientific men of merit but of small income. This plan was to pay the life membership fee to the permanent secretary for certain men selected by themselves, often after consultation with Dr. Brashear.

A very considerable number of the life members of the Association owe their life memberships to this unobtrusive generosity on the part of the Misses Smith, and the permanent funds of the association, the income of which is devoted to the advancement of scientific research, has been considerably enlarged in this way.

Those of the members of the association who have been fortunate enough to enjoy the acquaintance of Miss Smith will miss her greatly.

L. O. H.

\section{THE SUMMER MEETING OF SECTION E OF THE AMERICAN ASSOCIATION}

The following notice has been sent to all geologists and geographers, some 950 in number :

For several reasons it has been decided to hold no summer meeting of Section $\mathrm{E}$ early in July. (1) These summer meetings have been attended so largely by educators in the eastern states that it seemed unwise to hold a summer meeting at the time of the meeting of the National Education Association, the week beginning July 4. (2) Mr. R. W. Brock, director of the Canadian Survey, has decided that it will be impossible to hold a meeting in Canada this summer as was suggested at the Boston meeting. (3) Many geologists will attend the National Geologic Congress in August and September.

The geologists and geographers were asked to express their opinion in regard to the wis- 